\title{
O FUNCIONAMENTO DO EQUÍVOCO NO DISCURSO: O CONFLITO DE SENTIDOS OPOSTOS NO DISCURSO POR DIREITOS LGBTS
}

\author{
FREDERICO SIDNEY GUIMARÃES ${ }^{1}$
}

\author{
Instituto de Letras, Laboratório Arquivos do Sujeito \\ Universidade Federal Fluminense \\ R. Prof. Marcos Waldemar de Freitas Reis, $s / n^{\circ}$ - São Domingos \\ Niterói, RJ - CEP 24210-201 \\ fredsidabol.com.br
}

\begin{abstract}
Resumo. Este artigo propõe uma análise do funcionamento do equívoco no discurso por direitos LGBTs. A partir do aporte teórico da Análise do Discurso de Pêcheux e Orlandi, efetua-se um gesto de leitura para analisar as indicações de que sujeitos estariam equivocados. A análise, portanto, se concentra no efeito de sentido do equívoco, entendido como constitutivo do processo discursivo. Os corpora de análise se constituíram de recortes nas discussões da rede social facebook, a partir da indicação por parte do discurso militante LGBT de que um sujeito estaria equivocado a apoiar um suposto candidato contrário aos direitos dos LGBTs.
\end{abstract}

Palavras-chave: Análise do Discurso; equívoco; ideologia.

\begin{abstract}
This article proposes an analysis of the functioning of the misconception in the LGBT rights discourse. Based on Discourse Analysis theory of Pêcheux and Orlandi, a reading gesture is made to analyze the indications that Subjects would be misconceptioned. The analysis, therefore, concentrates on the effect of the meaning of the equivocation, understood as constitutive of the discursive process. The corpora analysis was constituted by cuts in the discussions of the facebook social network, from the indication by the militant speech LGBT that a Subject would be misconceptioned on his support a supposed candidate against the rights of the LGBTs.
\end{abstract}

Keywords: Discourse Analysis; misconception; ideology.

Toda língua está necessariamente em relação com o "não está", o "não está mais", o "ainda não está" e o "nunca estará" da percepção imediata: nela se inscreve assim a eficácia omni-histórica da ideologia como tendência incontornável a representar as origens e os fins últimos, o alhures, o além e o invisível.

Pêcheux (1990[1982])

\footnotetext{
${ }^{1}$ Doutor em Estudos de Linguagem pela UFF. Professor da rede municipal e estadual do Rio de Janeiro.
} 


\section{APRESENTAÇÃO}

A circulação de um dizer é considerada como um dos três momentos do processo discursivo constituído através de uma certa conjuntura e uma certa condição (ORLANDI, 2012). A partir desse pressuposto, este trabalho reflete sobre a circulação do dizer sobre o homossexual, pelo próprio homossexual, no processo conflituoso de tomada da posição política. O conflito dos sentidos e o caráter incompleto da linguagem em relação à vontade da apropriação dos acontecimentos pelo sujeito pragmático ${ }^{2}$ constituem o equívoco pela ilusão de dizer sobre aquele que é, não seria mais e, talvez, nunca tenha sido.

Através da filiação teórica na Análise do Discurso desenvolvidas inicialmente na França por Pêcheux (2010[1969]) e Orlandi (1999) $)^{3}$ no Brasil, propõe-se, nesse trabalho, a análise da indicação imaginária do equívoco na fala de um sujeito constituído pela evidência de se classificar como homossexual. Tal sujeito apoia uma posição política imaginariamente contrária à segurança desse mesmo sujeito por conta exatamente dessa evidência de se dizer gay. Ou seja, um $g a y^{4}$ que se apoia nos sentidos de um discurso imaginariamente contrário à segurança dos próprios gays. Tem-se, de um lado, um sujeito que assume sua posição política acusada de ser equivocada. Por outro lado, na parte que acusa o equívoco, o discurso militante favorável aos direitos dos homossexuais, que não deixa de ter também seus sujeitos inseridos no equívoco que constitui o discurso.

O corpus de análise é um recorte do arquivo de pesquisa sobre a disputa discursiva pelos direitos dos homossexuais. Trata-se de uma seleção nas publicações do grupo Todos contra a Homofobia ${ }^{5}$, da rede social facebook. Esse recorte se insere na temática do equívoco do sujeito que se diz pelo que dizem dele e, com isso, formula uma série de sentidos através de um pressuposto afetado por uma certeza imaginária. A situação particular desse recorte apresenta um sujeito que se diz homossexual apoiando um político $^{6}$ que se diz contra os direitos dos homossexuais. Evidenciam-se, então, dois campos imaginariamente opostos, delimitando as posições pré-determinadas em que outros imaginários estipulam como tais sujeitos deveriam se posicionar em suas posições políticas-discursivas.

A constituição do corpus desse trabalho se pautou em dois momentos: por um lado, pelo vídeo $^{7}$ postado em perfil público do sujeito gay apoiando um político contrário aos gays; e, por outro lado, esse vídeo teve sua circulação no grupo do facebook em questão demonstrando uma postura crítica sobre a receptividade desse vídeo. Trata-se da configuração de duas forma-sujeito (PÊCHEUX, 1995[1975]): uma em que o sujeito se

\footnotetext{
${ }^{2}$ É o sujeito que tem a certeza de ser uno, de ser ciente de seus sentidos e submetido à imperiosa necessidade da homogeneidade lógica.

${ }^{3}$ Levando em consideração que há várias linhas teóricas com definições especificas sobre discurso e o método de análise, a partir de então o uso do termo "Análise do Discurso" se refere à linha teórica especificada.

${ }^{4} \mathrm{O}$ uso sinonímico dos termos gay e homossexual faz parte da circulação presente nos discursos por direitos dos homossexuais.

${ }^{5}$ Endereço de acesso às postagens do grupo, é necessário ter um perfil registrado na plataforma facebook: https://www.facebook.com/groups/tchlt/?fref=ts.

${ }^{6}$ Não se analisa o assujeitamento desse político, ou seja, o político em questão não é referido nesse texto em sua forma-sujeito.

${ }^{7} \mathrm{O}$ vídeo está disponível para acesso público na plataforma social youtube no seguinte endereço eletrônico: https://www.youtube.com/watch?v=qbT85kXCbFg.
} 
constitui pela sua opinião; a outra é configurada pela reação à opinião que constituiu o sujeito tido como equivocado. Tem-se, então, a noção de que o sujeito toma forma conforme seu posicionamento no discurso.

$\mathrm{Na}$ arena dessa disputa, encontra-se a relação de dizeres que acusam esse sujeito homossexual em questão como negando a própria segurança ao se aliar a um discurso supostamente violento e imaginariamente considerado como tendo origem no político ao qual o sujeito homossexual deveria se posicionar contra. Na acusação dos que querem delimitar o equívoco desse sujeito como algo a ser controlado e superado, se inscreve a ideia, na Análise do Discurso, de que o equívoco é constitutivo nos processos discursivos. Isso quer dizer que os que acusam também se equivocam.

Não se distingue aqui o equívoco no imaginário do equívoco no linguístico ${ }^{8}$. Ambos se colocam como constitutivos do discurso: a certeza imaginária e o impossível da língua. Considera-se, assim como Orlandi, que o "discurso não é indiferente à língua" (2007, p. 22).

Sendo assim, num primeiro momento, apresenta-se a relação entre a linguagem, ideologia e o inconsciente como o lugar próprio dos equívocos. No segundo momento, colocam-se em análise os recortes inscritos no equívoco constitutivo do discurso.

\section{A ANÁliSE DO DISCURSO E O RITUAL DA EVIDÊNCIA COM FALHAS}

A ideia de indicação imaginária do equívoco é baseada na certeza de que um sujeito não pode se posicionar em um outro dizer. Ela se apresenta como uma certeza em si, compondo um imaginário discursivo presente nas afirmações do caso que propomos analisar.

Desta forma, temos a princípio dois efeitos de evidência dentro de um escopo previamente colocado numa conjuntura discursiva: 1 - a identificação do sujeito a uma ontologia homossexual; e 2 - a evidência de cristalização dos sentidos nos discursos em campos opostos, indicando que as posições dos sujeitos nos discursos não poderiam transitar entre esses sentidos opostos. É necessário enfatizar que a identificação, seja ou ao efeito de se designar como algo, ou à certeza dos sentidos no discurso, é constituída pelos processos ideológicos e afetados pelo inconsciente (PÊCHEUX 1995[1975]). Tanto se dizer gay como imaginar um conflito de sentidos estão inseridos no efeito próprio da ideologia e do inconsciente nos processos discursivos.

A ideologia, nesse caso, é o que alimenta a evidência do sentido. Como efeito, a própria ideologia se materializa em posições e disputas, caracterizando a formação ideológica (PÊCHEUX, 1995[1975]). O efeito da formação ideológica proporciona uma ideia de totalidade no sujeito que se supõe controlador do seu dizer e, assim, permite que ele se mantenha em uma segurança de si de forma imaginária:

\footnotetext{
${ }^{8}$ Isso não quer dizer que não possa haver uma análise com base nessa distinção. Não é o caso nesse texto. O ponto de encontro do equívoco com o imaginário é entendido também a partir do funcionamento do equívoco no linguístico, conforme a noção da não transparência da língua e a possibilidade do dizer ser um dizer outro.
} 
Os indivíduos são 'interpelados' em sujeitos falantes (em sujeitos de seu discurso) por formações discursivas que representam 'ㅁa linguagem' as formações ideológicas que lhes são correspondentes. (PÊCHEUX, 1995, p. 214[1975]; sublinhado nosso)

A linguagem, então, é o lugar da materialização dos efeitos da ideologia (PÊCHEUX, 1995[1975]). A formulação linguística perpassa pelas evidências do sentido para poder constituir um imaginário de que algo está sendo dito de forma inquestionável. Essa materialização da ideologia na linguagem é composta através do dito pressupor algo que não pode ser dito, alimentando uma ordenação do dizer baseada em certezas de sentidos constituintes da noção de Formação Discursiva (PÊCHEUX, 1995[1975]). O processo discursivo, então, é formado pela relação entre a formação ideológica e a formação discursiva.

Apesar da construção das certezas dos sentidos estar pautada pelas formações ideológicas, elas não se mantem cristalizadas e categorizadas. Por conta disso, têm-se os efeitos de evidência que caracterizam o imaginário do sujeito. Esse imaginário é capaz de fazer o sujeito ter certeza de algo que ele diz ser e também de fazer esse sujeito considerar os sentidos dos dizeres como se estivessem em campos opostos bem delimitados e isolados. Esse efeito de evidência em algum momento falha para se constituir um equívoco.

Dito de outra forma, a ideologia toca o inconsciente pelo viés do impossível. O lapso e o ato falho marcam o impossível de uma dominação ideológica fora de toda contradição. A série dos efeitos aqui resumidos pelas figuras do lapso e do ato falho infecta, assim, sem parar, toda a ideologia dominante, no próprio interior das práticas, nas quais tende a se realizar. (PÊCHEUX, 2015[1984], p. 16)

Se o processo discursivo se compusesse em algo completo e perfeito, não haveria equívocos e o efeito das formações ideológicas bastaria para manter a continuidade dos sentidos. No equívoco localizamos a afetação do inconsciente na evidência da ideologia, configurando a construção do sujeito que se posiciona nos seus dizeres inseridos nos processos discursivos.

A consistência das certezas pela posição ideológica é alimentada por outros dizeres, os já ditos que compõem o imaginário do sentido ser colocado como inquestionável. $\mathrm{O}$ funcionamento dos já ditos corrobora a funcionamento das formações ideológicas através de uma ordem discursiva própria, caracterizando mais ainda o aspecto material do discurso através das formulações linguísticas. Essa materialidade do já dito é contextualizada por Pêcheux ao tratar do interdiscurso (PÊCHEUX, 1995[1975]).

O entendimento do interdiscurso contextualizado na Análise do Discurso deve levar em consideração um outro conceito que o compõe: o pré-construído.

Foi isso que levou P. Henry a propor o termo pré-construído para designar o que remete a uma construção anterior, exterior, mas sempre independente, em oposição ao que é 'construído' pelo enunciado. Tratase, em suma, do efeito discursivo ligado ao encaixe sintático. (PÊCHEUX, 1995[1975], p. 99) 
O pré-construído entendido enquanto elemento do interdiscurso atua no processo discursivo para dar consistência à certeza do sujeito "impondo-dissimulando-lhe seu assujeitamento sob a aparência da autonomia, isto é, através da estrutura discursiva da forma-sujeito" (PÊCHEUX, 1995[1975], p. 163/164).

A constituição do sujeito determinada pela sua inserção numa formação ideológica é acompanhada por sentidos já existentes que sustentam o sujeito nessa posição e determina a forma como suas ideias serão materializadas na língua. $\mathrm{O}$ equívoco no discurso atua nesse funcionamento, sem deixar o sujeito se perceber desse equívoco. Isso permite ao sujeito atuar através de sua certeza, inclusive quando se considera como capaz de categorizar outros sujeitos e os sentidos sobre os quais essas categorias imaginárias de sujeitos os caracterizariam como aptos a falar.

Assim que a indicação imaginária do equívoco se coloca discursivamente como um próprio equívoco. É demonstrar um equívoco do outro sem se dar conta de que se está num equívoco. O trabalho metodológico do corpus proposto para análise nesse artigo considera a seleção dos enunciados a partir de posições dos sujeitos delimitadas em suas certezas. Pelas palavras de Pêcheux (1995[1975]), seriam os bons sujeitos em suas modalidades subjetivas das identificações ideológicas.

Em termos políticos, temos uma consequência histórica do imaginário do equívoco, pois certezas são condicionadas aos posicionamentos ideológicos possibilitados por tal imaginário. Assim, temos o equívoco como constitutivo do discurso, envolvendo a questão do sujeito historicamente determinado e submetido ao contraditório próprio da história. "A irrupção do equívoco afeta o real da história" (PÊCHEUX; GADET, 2004[1983], p. 64). Logo, o sujeito e a história estão atrelados à condição do equívoco como constituindo o discurso. Ou seja, não há sujeito senão pelo imaginário de suas certezas e não há história senão pela contradição que demanda uma disputa para tentar estabilizar o seu sentido. O problema é que essa disputa é feita exatamente por sujeitos em seus imaginários. Nesse ponto, tem-se a noção da forma-sujeito.

A partir da teoria não-subjetiva da subjetividade, as práticas não podem ser consideradas como não contendo um sujeito. Por outro lado, as práticas também não são dos sujeitos, como se eles pudessem fazer escolhas conscientes de suas práticas. As práticas estão, então, submetidas à ideia da forma-sujeito, que é a constituição desse sujeito pelos processos discursivos que irá materializar suas ideias através da prática discursiva. Tratase do sujeito formado segundo suas certezas ideológicas.

As modalidades subjetivas da forma sujeito (PÊCHEUX, 1995[1975]) são caracterizadas em três aspectos: bom sujeito, idealmente identificado com uma formação ideológica específica; a do mau sujeito, quando ocorre um deslize no efeito de reconhecimento na tal formação ideológica; e, a partir do mau sujeito, supor uma terceira modalidade, que seria a constituição de uma nova forma, já inserida já numa outra formação ideológica específica.

Essa teoria das modalidades permitiu uma discussão entorno dos processos de identificações e desidentificações. Indursky (2008), leva em consideração o desdobramento e a fragmentação da forma-sujeito através do funcionamento das identificações aos sentidos postos no discurso. 
O processo de identificação e desidentificação não condiz com a afirmação de uma liberdade do sujeito, apenas serve para demonstrar que o desdobramento da forma-sujeito é constituído por diferentes posicionamentos ideológicos. A análise é feita pelo enunciado, já dado e a posteriori. Não caracteriza em si uma categorização de um sujeito em sua totalidade e essencialidade. Considerar o trâmite entre o estar identificado e o não estar identificado permite analisar como o equívoco trabalha nesse processo de identificação.

Em um determinado momento, sob o efeito de determinadas condições de produção, o sujeito do discurso pode romper com o domínio de saber em que estava inscrito e, em consequência, identificar-se com outra FD (formação discursiva). [...] quando o sujeito do discurso desidentificase de uma determinada FD é porque, de forma inconsciente, ele já está identificado com outro domínio do saber. (INDURSKY, 2008, p. 15; grifos nossos)

Sendo o sujeito sempre afiliado a uma ideologia, essa ideologia não se efetua sem falhas, permitindo o equívoco atuar e direcionar o sujeito a uma outra formação ideológica. Por outro lado, o equívoco também é uma forma de manter o sujeito em suas certezas, já que sem essa segunda forma de funcionamento do equívoco não haveria a certeza do sujeito de dizer o que acha que ele é e de acusar um outro sujeito de equivocado. Sem a percepção do equívoco, o sujeito se mantém seguro no seu dizer, mas essa segurança é quebrada quando o equívoco não garante as certezas imaginadas. Afinal, ao se sentir seguro, é sinal de que nada ameaça essa certeza da segurança.

Vejamos, então, como funcionaram essas certezas (equivocadas) numa discussão em torno dos direitos dos homossexuais.

\section{O QUE PODE UM SUJEITO DIZER E FAZER?}

A postagem que constitui o corpus dessa reflexão sobre a tomada de posição e sobre o equívoco do sujeito no discurso foi publicada no grupo Todos Contra Homofobia, Transfobia e Lesbofogia da rede social facebook. Se pensarmos num caminho de exposição da postagem, há o compartilhamento de um artigo da Revista Lado A cujo título é: "O que dizer sobre gays que defendem Jair Bolsonaro para Presidência?"

A chamada do título, num grupo que se propõe a combater a reação negativa aos direitos dos homossexuais, condiz com a resposta prévia a essa pergunta. Pressupõe-se, ideologicamente, que já se sabe o que se deve dizer sobre o gay que defende um político contrário ao direito do gay. A pergunta do título da publicação já está na evidência de que gays não poderiam defender tal candidato.

A questão é que essa pergunta, considerando a Formação Discursiva favorável aos direitos dos homossexuais, toma como evidente o fato de que o gay, por ser gay, deve apoiar a causa gay. Só por essa linha ideológica, há uma determinação de como deveriam seguir as identificações dos sujeitos. Tais sujeitos deveriam estar imaginariamente

\footnotetext{
${ }^{9}$ Repostado no perfil do grupo do facebook todos contra homofobia, transfobia e lesbofobia em 29 de março de 2016.
} 
inscritos numa formação discursiva em que o que pode ser formulado linguisticamente deve indicar semanticamente o sentido favorável à causa homossexual.

Nesse ponto, a prévia certeza ideológica do pergunta-enunciado em questão esbarra num ponto essencial da configuração da forma-sujeito designada nas enunciações em questão: a formação ideológica e as afetações inconscientes dos sujeitos estão na falha própria da palavra designar a coisa que está sendo dita, que nesse caso é a condição ôntica do homossexual expressa, inclusive, pelo nome próprio.

$$
\text { [(Fulano) é gay] }
$$

Pêcheux (1995[1975]) ao refletir sobre a construção das evidências nas ciências descritivas, discorre sobre a consideração do nome e o funcionamento do processo de referência.

\begin{abstract}
A característica dessas 'ciências descritivas' é a de fornecer uma espécie de Estado Civil do Universo, tratando a 'realidade' como o conjunto das 'coisas', sendo cada uma designada por seu nome próprio, como Kepler, Berlim, Vênus, para retomar os exemplos de Frege. Ora, eis o ponto decisivo, essa designação pelo nome próprio implica, correlativamente, a possibilidade de designar 'a mesma coisa' por uma perífrase, tal como 'aquele que descobriu' [...]. (PÊCHEUX, 1995[1975], p. 100)
\end{abstract}

O que temos nesse caso é a indicação do gay e sua assimilação a um estado ôntico, definidor e representante de um ser. Ser caracterizado como um gay é ser gay por si mesmo. A relação entre o nome e o adjetivo toma um funcionamento evidente de que a coisa (sujeito) está sendo designada como se fosse irredutível. O sujeito e sua característica se mesclam num processo de significação único, podendo facilmente transformar o adjetivo que caracterizaria uma pessoa gay em um substantivo definidor de um sujeito em si. Se considerarmos a colocação do nome próprio, seria como substituir o gay por um nome de um gay a fim do efeito semântico se manter na evidência ideológica:

$$
\text { [o que dizer (sobre gays) } \left.\rightarrow \text { o que dizer sobre (Smith Hays })^{10}\right]
$$

O uso desse nome próprio está exposto tanto no artigo publicado no grupo do facebook como também é o nome do perfil público do sujeito que publicou o vídeo defendendo o deputado que se posiciona contrário aos direitos dos homossexuais. Como nos indicou Pêcheux (1995[1975]), esse nome não está designando a coisa em si, o ser, apenas está designando o imaginário que coordena o processo de significação em torno do que se sabe sobre uma determinada situação.

$$
\text { [Ele é gay } \rightarrow \text { aquele que é gay } \rightarrow \text { o gay é aquele ali] }
$$

O ponto principal dessa análise é que a significação só se torna possível através do préconstruído presente na criação de sentidos sobre como poderia um gay se posicionar politicamente contra o gay. É nesse ponto que atua a indicação dos possíveis imaginários

${ }^{10}$ É o nome posto como sendo do sujeito do vídeo em questão colocado no seu perfil público da rede social facebook. 
dos equívocos nas falas tanto do sujeito gay que apoia o político contrário aos seus direitos como também no sujeito militante gay que se coloca numa certeza de dizer que o outro sujeito está equivocado em se posicionar contra si mesmo. Ou seja, temos a língua e a história submetidas ao equívoco.

O equívoco, conforme tratado nesse artigo, não está no sujeito, mas no discurso. O sujeito não está equivocado, pois, ao entrar no processo de sentidos do discurso baseado nas certezas ideológicas, ele não se coloca como equivocado. O equívoco reclamado pelo discurso militante, portanto, é a ilusão de achar que o sujeito está sendo designado em uma indicação direta e irredutível através das palavras que indicam suas qualidades, identificações ou realizações.

O equívoco do gay se posicionar contra si mesmo só tem sentido dentro de uma formação discursiva própria, que, pelo pré-construído, irá conduzir a formulações enunciativas para demonstrar como ele estaria agindo contra uma suposta segurança para ele mesmo. Se esse sujeito estivesse posicionado numa defesa dos direitos dos homossexuais, o discurso militante teria uma lógica discursiva para questionar a coerência dos sentidos emanados dessa fala destoante, aproximando esse sujeito a uma suposta desidentificação. Nessa hipótese de o sujeito fazer parte de uma militância favorável aos direitos dos homossexuais, poderíamos considerar uma lógica discursiva equivocada quando a prática militante não condiz com a formação discursiva dessa militância. Para fazermos esse tipo de análise, o tal sujeito precisaria demonstrar, em seus enunciados, a identificação com as formações ideológicas da militância homossexual. Tal análise, portanto, seria restrita ao filtro que reduziria o sujeito à sua sexualidade associada à formação discursiva da militância favorável aos direitos dos homossexuais. Não é o caso em questão. Voltemos, então, para análise dos supostos equívocos no funcionamento das formulações linguísticas.

Se considerarmos a qualificação dos adjetivos na constituição ôntica desses sujeitos nos discursos, é possível empreender uma intricada rede semântica para construir um ser devidamente suprido pelos signos linguísticos para dar conta da referência de suas características e qualidades. Além de gay, poderiam entrar aspectos sociais referentes à pobreza, riqueza, escolaridade, etc. Ou também considerar aspectos históricos / culturais, como: machismo, questão de gênero e demais valores culturais referentes à inserção desse sujeito em suas relações sociais.

Uma pesquisa empírica poderia mapear as inúmeras possibilidades da constituição desse sujeito para supostamente explicar um posicionamento político considerado como equivocado. Por outro lado, se considerarmos o processo discursivo e a premissa básica da língua se referir a um sentido e não exatamente a uma coisa em si, todo esse mapeamento empírico encontrará seu próprio equívoco inerente. Para expressar suas observações e conclusões, o pesquisador precisará se inserir no mesmo processo de linguagem que conduz o processo discursivo determinado por posições ideológicas e afetações inconscientes. Isso impossibilita, então, uma resposta objetiva à pergunta do que poderia um sujeito dizer ou fazer.

Uma análise do sujeito numa classe econômica (pobre), por exemplo, não o totaliza na sexualidade (homossexual), escolaridade, religião, etc. Assim fica exemplificado a contradição que é inerente ao processo histórico que determina a ideologia ser um ritual 
com falhas. Aqui, podemos entender o que nos diz Pêcheux e Gadet sobre o equívoco aparecer "exatamente como o ponto em que o impossível (linguístico) vem alia-se à contradição (histórica)" (2004[1983], p. 64).

Estar preso ao equívoco no discurso não é um problema, não é algo que se deve procurar evitar. Pensando pela Análise do Discurso, seria algo que possa ser considerado e observado num tempo posterior, depois da formulação supostamente equivocada. $\mathrm{O}$ militante, o observador teórico e qualquer sujeito (do discurso) estão submetidos aos limites da linguagem. $\mathrm{O}$ mesmo funcionamento do equívoco ao considerar a qualidade de um ser como sendo a constituição totalizante desse ser está presente também no discurso do sujeito acusado de equivocado pela militância política homossexual. Ou seja, o tal sujeito equivocado, segundo a militância política favorável ao homossexual, também caracteriza o militante homossexual para formular suas certezas ideológicas e constituir verdades que não dão conta do aspecto diverso e falho das designações. O imaginário do equívoco precisa se impor para o sujeito se achar na certeza de dizer que o outro é equivocado.

Em sua justificativa, o sujeito homossexual identificado com o discurso do político contrário ao homossexual expõe uma certeza para a escolha de seu voto.

O Jair Messias Bolsonaro é uma pessoa honestíssima, uma pessoa de ética, uma pessoa de moral e, sinceramente, isso já seria suficiente para votar nele". ${ }^{11}$ (grifos nossos)

A construção dessa certeza sobre a qualidade de um sujeito coloca em funcionamento a designação na formulação

[Aquele que é (adjetivo), (construção determinando uma ação) $\rightarrow$ Aquele que é honesto, merece meu voto.]

Do lado oposto a essas certezas nessa formação ideológica, teríamos:

$$
\text { [Aquele que é (gay), (não vota no Bolsonaro).] }
$$

Quando o sujeito homossexual favorável ao político contrário à causa homossexual justifica a sua posição, ele distingue em suas formulações dois tipos de homossexual: o gay e o ativista (ativismo).

Quanto a parte do gay, quanto a parte do homofóbico, Jair Bolsonaro ele pensava, ele tinha uns conceitos bem errados sobre gays, mas ele está mudando. Alguém está alertando ele sobre a grande diferença entre o gay e o ativista, e o ativismo. Não é? Porque o ativismo ele é invasivo, ele é agressivo. ${ }^{12}$ (grifos nossos)

[Aquele que é (ativista), (é invasivo).]

\footnotetext{
${ }^{11}$ Recorte selecionado do vídeo em questão.

12 Recorte selecionado do vídeo em questão.
} 
Além das considerações dessa certeza de qualificar o lado oposto da identificação ideológica, há a desconsideração do funcionamento do termo invasivo ou agressivo, pois são termos que também são postos em circulação pelo discurso favorável aos direitos dos homossexuais. O termo agressivo nas chamadas da militância gay diz respeito ao aspecto da segurança do homossexual, quando há acusação de agressões aos sujeitos que agem e se dizem homossexuais.

Nos comentários da postagem do Grupo todos contra homofobia, lesbofobia e transfobia, um espectador identificado com a militância resumiu o caso do gay que apoia um político contrário com uma única palavra: "Desserviço".

Nesse jogo de sentidos, a ação desse gay que apoia o político contrário ao gay prestaria um desserviço à militância por direitos aos homossexuais, incluindo a preocupação com a segurança do homossexual. Sem querer considerar o funcionamento do efeito de sentido equivocado de que não necessariamente seria um desserviço à militância, cabe considerar que, dentro das formações ideológicas dos pares opostos em questão, ambos têm suas certezas sobre segurança e invasão. Para o gay que apoia o político contrário ao gay, ele não está se sentindo inseguro por conta da militância política contrária ao gay, pelo contrário. Nas considerações do sujeito do vídeo analisado, é a militância que é agressiva, invasiva.

\section{EFEITOS DE CONCLUSÃO}

A circulação desses dizeres sobre os equívocos de sujeitos considerados previamente em suas posições políticas por conta do imaginário do que eles supostamente seriam é, em si, um próprio equívoco. Esse equívoco foi considerado nas análises como constitutivo do processo discursivo, pois sem ele não seria possível manter as certezas que categorizam os tais sujeitos e que determinam em quais posições políticas eles devem estar.

Através do funcionamento das formações ideológicas e formações discursivas, foi possível analisar como estruturas linguísticas semelhantes - [Aquele que é (adjetivo), (construção determinando uma ação)] - compõem os dizeres dos dois lados posicionados como opositores nessa disputa por sentidos. Ambos submetidos ao mesmo funcionamento do equívoco de considerar a designação de um sentido como sendo a essência de algo em si.

Foi analisado, com isso, um funcionamento do equívoco no discurso. Esse equívoco não estaria exposto na língua, mas se observa através do funcionamento do próprio processo discursivo. Entendemos que o sujeito homossexual acusado de estar equivocado pelo discurso militante gay faz parte do próprio equívoco em tal discurso, sem negar um funcionamento do equívoco no discurso do sujeito em questão. Consideramos que o sujeito inserido em suas certezas ideológicas não estaria equivocado como sugere o discurso militante, pois está de acordo com os sentidos do discurso baseado nas suas certezas ideológicas.

Sendo assim, o equívoco apontado pelo discurso militante ao sujeito em questão, portanto, é a ilusão de achar que o sujeito está sendo designado em uma indicação direta e irredutível através das palavras que indicam suas qualidades, identificações ou 
realizações. É esse mesmo equívoco que está no discurso do sujeito em questão ao usar da mesma ilusão para caracterizar aqueles que estão em oposição a sua posição ideológica.

Assim que encerramos nossa análise parafraseando Pêcheux, refletindo como esses equívocos próprios do processo discursivo demonstram o funcionamento da língua que está em relação com o não está. Essa ausência, o invisível, o não percebido, é o constitutivo das nossas certezas e alimentam os deslizes e as eternas reformulações dos sentidos.

\section{REFERÊNCIAS}

INDURSKY, F. Unicidade, desdobramento, fragmentação: a trajetória da noção de sujeito em AD. Em: MITTMANN, S.; GRIGOLETO, E.; CAZARINI, E. (Orgs). Práticas discursivas e identitárias: sujeito e língua. Porto Alegre: Nova Prova, 2008.

ORLANDI, E. Discurso e texto: formulação e circulação dos sentidos. Pontes: Campinas, 2012. ORLANDI, E. As formas do silêncio: no movimento dos sentidos. Campinas: Ed. Unicamp, 2007.

ORLANDI, E. Análise de discurso: princípios e procedimentos. Campinas: Pontes, 1999.

PÊCHEUX, M. Ousar pensar, ousar se revoltar: ideologia, marxismo e luta de classes. Décalages, vol. 1, 2015[1984].

PÊCHEUX, M. Análise Automática do Discurso. Em: GADET, F.; HAK, T. Por uma Análise Automática do Discurso. Trad. Bras. 4a . ed. Campinas: Ed. da Unicamp, 2010[1969].

PÊCHEUX, M. Semântica e discurso: uma crítica à afirmação do óbvio. Campinas: Ed. Unicamp, 1995[1975].

PÊCHEUX, M. Delimitações, inversões, deslocamentos. Cadernos de Estudos Linguísticos, $\mathrm{n}^{\circ}$. 19, Campinas, IEL/UNICAMP, 1990[1982].

PÊCHEUX, M; GADET, F. A língua inatingível: o discurso na história da linguística. Campinas: Pontes, 2004[1983].

Artigo recebido em: out. de 2018.

Aprovado e revisado em: abril de 2019.

Publicado em: dezembro de 2019.

Para citar este texto:

GUIMARÃES, Frederico Sidney. O funcionamento do equívoco no discurso: o conflito de sentidos opostos no discurso por direitos LGBTS. Entremeios [Revista de Estudos do Discurso, ISSN 2179-3514, on-line, www.entremeios.inf.br], Seção Estudos, Programa de Pós-Graduação em Ciências da Linguagem (PPGCL), Universidade do Vale do Sapucaí (UNIVÁS), Pouso Alegre (MG), vol. 18, p. 81-91, jan. - jun. 2019.

DOI: http://dx.doi.org/10.20337/ISSN2179-3514revistaENTREMEIOSvol18pagina81a91 